\title{
Implementasi Rangka Untuk Sepeda Motor Sport Elektrik Setara 250cc
}

\author{
Nur Alif Fitria Nugraha, Andhika Estiyono, dan Arie Kurniawan \\ Departemen Desain Produk Industri, Institut Teknologi Sepuluh Nopember (ITS) \\ e-mail: andhikae@prodes.its.ac.id
}

\begin{abstract}
Abstrak-Untuk mengurangi emisi dari kendaraan bermotor, salah satu yang dapat dilakukan adalah dengan beralih dari kendaraan dengan mesin bakar ke kendaraan listrik. Jika melihat pada konsumsi energi per kilometernya, sepeda motor listrik memiliki efisiensi yang tinggi sehingga akan cocok jika dipakai sebagai solusi. Meskipun kendaraan umum bisa menjadi solusi masalah ini, namun memiliki kendaraan pribadi dapat memberi dampak psikososial yang positif dengan cara membanggakan kendarannya baik dari performa, maupun tingkat personalisasi kendaraannya. Pada pasar sepeda motor bermesin bakar di Indonesia, prestise seringkali dikaitkan dengan ukuran volume dari mesin. Dari semua kendaraan yang dipasarkan di Indonesia, kapasitas 250cc merupakan ukuran mesin terbesar yang tersedia secara merata. Sehingga untuk membuat sepeda motor listrik memiliki nilai positif pada kondisi psikososial pemiliknya, maka sepeda listrik setidaknya harus dapat bersaing pada segi performanya dengan sepeda motor kelas 250cc. Untuk itu diperlukan rangka yang aman untuk menahan tenaga yang setara dengan sepeda motor 250cc serta dapat menunjang kebutuhan personalisasi pengendaranya.
\end{abstract}

Kata Kunci-Psikososial, performa, 250cc, rangka, personalisasi.

\section{PENDAHULUAN}

$\mathbf{J}^{\mathrm{K} A}$ KA dibandingkan dengan moda transportasi bermesin lainnya, sepeda motor termasuk kendaraan ringan. Sehingga konsumsi energinya pun akan lebih kecil dibandingkan dengan kendaraan jenis lain. Jika sepeda motor dibuat elektrik, dengan konsumsi energi sekitar $0,03 \mathrm{~kW} / \mathrm{km}[1]$, sepeda motor memiliki rasio konsumsi energi per kilometer terkecil. Sehingga dapat menjadi salah satu solusi mengurangi polusi.

Keberadaan sepeda motor listrik di Indonesia saat ini mulai umum. Dengan tiga produsen utama yang merupakan produsen dalam negeri, yakni Viar, Gesits, dan Selis. Meskipun sudah ada beberapa brand yang memproduksi sepeda motor listrik, namun hingga saat ini jenis sepeda motor listrik yang ada di Indonesia seluruhnya berjenis skuter.

Untuk sebagian masyarakat, skuter dapat memenuhi kebutuhan untuk commuting. Namun untuk pasar penyuka sepeda motor, serta komunitas, kelompok ini tidak hanya menggunakan sepeda motor untuk pergi dari titik A ke B. Namun penggunaan sepeda motor juga dipakai untuk dijadikan personal branding karena faktor usia, tingkat pendidikan, jenis pekerjaan, hingga pendapatan dan gengsi dapat mempengaruhi keputusan untuk membeli kendaraan[2]. Selain itu kepemilikan kendaraan pribadi dapat meningkatkan kondisi psikososialnya[3]. Karena dengan memiliki kendaraan tersebut
Tabel 1

Performa sepeda motor bakar kelas 250cc

\begin{tabular}{llll}
\hline \hline Sepeda Motor & hp & kW & Nm \\
\hline Kawasaki Ninja 250(2020) & 38.46 & 28.7 & 23.5 \\
Kawasaki Ninja 250(2018) & 38.21 & 28.5 & 23.5 \\
Kawasaki Ninja 250SL & 27.6 & 20.6 & 22.6 \\
Kawasaki Z250 & 31.5 & 23.5 & 21 \\
Kawasaki Z250SL & 27.61 & 20.6 & 22.6 \\
Kawasaki W250 & 17.75 & 13.2 & 18 \\
Kawasaki Versys X 250 & 33.5 & 25 & 21.7 \\
Kawasaki KLX 250 & 24.13 & 18 & 21 \\
Yamaha MT-25 & 35.53 & 26.5 & 23.6 \\
Yamaha R25 & 35.5 & 26.5 & 23.6 \\
Honda CBR250RR & 38.21 & 28.5 & 23.3 \\
Honda CRF250 Rally & 24.4 & 18.2 & 22.6 \\
Benelli Leoncino 250 & 26.8 & 20 & 21 \\
Benelli Pantagonian Eagle & 16.5 & 12.3 & 17.43 \\
Benelli TNT250 & 31.5 & 23.5 & 20 \\
Benelli TNT249s & 31.5 & 23.5 & 20 \\
Benelli TNT25 & 24.13 & 18 & 21.5 \\
KTM Duke 250 & 29.58 & 22.1 & 24 \\
KTM RC250 & 30.8 & 23 & 24 \\
Viar Vintech & 20.11 & 15 & 18 \\
Viar Cross X 250 EC & 25.47 & 19 & 23 \\
Viar Vortex 250 & 24.8 & 18.5 & 22.5 \\
Max & $\mathbf{3 8 . 4 6}$ & $\mathbf{2 8 . 7}$ & $\mathbf{2 3 . 6}$ \\
Average & $\mathbf{2 8 . 8}$ & $\mathbf{2 1 . 4 8}$ & $\mathbf{2 1 . 7 5}$ \\
Min & $\mathbf{1 6 . 5}$ & $\mathbf{1 2 . 3}$ & $\mathbf{1 7 . 4 3}$ \\
\hline \hline
\end{tabular}

biasanya kelompok ini mendapatkan beberapa keuntungan berupa perasaan aman, kebebasan untuk memilih, serta rasa prestisius.

Dari ketiganya, yang terpengaruh dari faktor kendaraannya adalah pada segi prestisius, umumnya ada beberapa hal yang seringkali dibanggakan oleh pemilik sepeda motor, diantaranya adalah brand, harga, performa, dan perasaan individualisme yang ditunjukkan dengan modifikasi. Sehingga, akan muncul kebanggaan memiliki kendaraan tersebut dan meningkatkan kepercayaan diri penggunanya.

Brand seringkali dikaitkan dengan lifestyle. Namun pada riset kali ini, brand tidak relevan karena tidak ditunjukkan. Pada segi performa, sepeda motor di Indonesia performa tinggi umumnya diacukan pada sepeda motor $250 \mathrm{cc}$. Hal ini karena $250 \mathrm{cc}$ merupakan volume mesin terbesar yang tersedia secara 


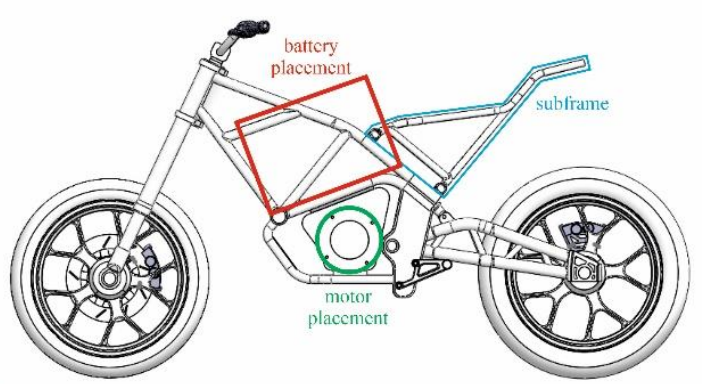

Gambar 1. Frame tubular.

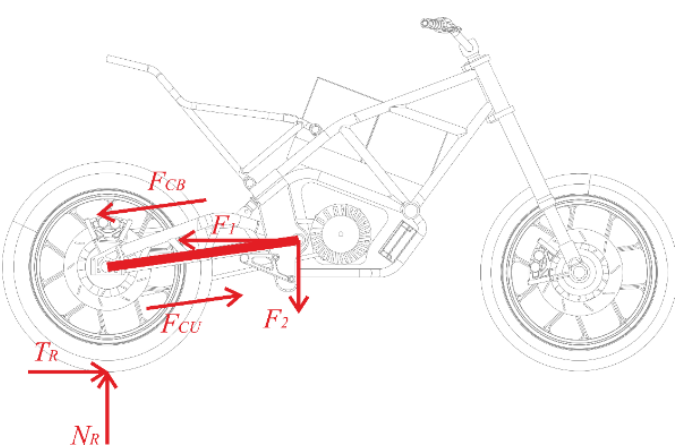

Gambar 2. Ilustrasi gaya yang terjadi saat akselerasi maksimum.

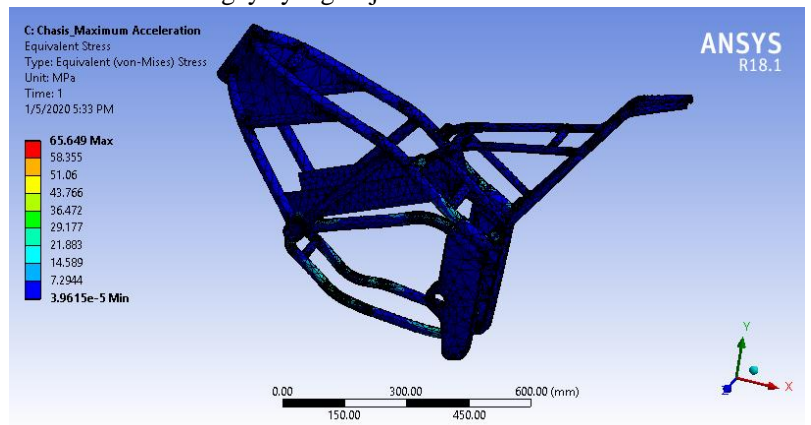

Gambar 3. Equivalent Stress, Max Acceleration.

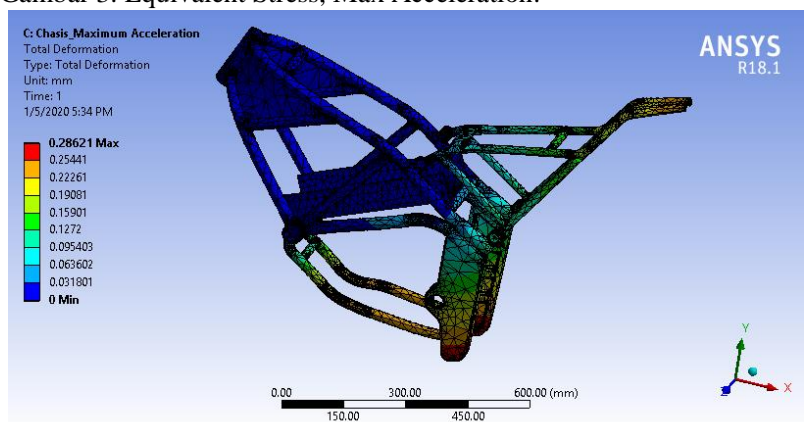

Gambar 4. Total Deformation, Max Acceleration.

merata. Individualisme pemilik sepeda motor sendiri biasanya ditunjukkan dengan memodifikasi sepeda motornya. Baik berupa modifikasi ringan, hingga ekstrim yang sampai merubah total gaya sepeda motornya.

Dengan kondisi pasar sepeda motor listrik Indonesia yang didominasi oleh skuter dengan performa rendah, kondisi tersebut membuat sepeda motor listrik saat ini tidak dapat memenuhi kebutuhan pasar dari sisi penyuka sepeda motor. Sehingga untuk memberikan diversifikasi pasar sepeda motor listrik di Indonesia dan memenuhi kebutuhan tersebut, maka
Tabel 2.

Properti rangka yang akan dipakai

\begin{tabular}{lll}
\hline \hline Parameter & Value & Unit \\
\hline Volume Chassis & 0.00747635 & $\mathrm{~m}^{\wedge} 3$ \\
Density material & 7850 & $\mathrm{~kg} / \mathrm{m}^{\wedge} 3$ \\
Massa rangka & 58.7 & $\mathrm{Kg}$ \\
Massa tanpa rangka & 131 & $\mathrm{~kg}$ \\
Massa total & 189.7 & $\mathrm{~kg}$ \\
\hline \hline
\end{tabular}

Tabel 3.

Spesifikasi Golden Motor 10kW kontinu

\begin{tabular}{ll}
\multicolumn{2}{c}{ Spesifikasi Golden Motor 10kW kontinu } \\
\hline \hline Voltage & $48 \mathrm{~V} / 72 \mathrm{~V} / 96 \mathrm{~V} / 12 \mathrm{~V}$ \\
Rated Power & $8 \mathrm{~kW}-20 \mathrm{~kW}$ \\
Efficiency & $91 \%$ \\
$\begin{array}{l}\text { Phase Resistance } \\
\text { (miliOhm) }\end{array}$ & $3.1 / 48 \mathrm{~V} ; 6 / 72 \mathrm{~V} ; 18 / 120 \mathrm{~V}$ \\
Phase Induction & $34 \mathrm{uH} / 48 \mathrm{~V} ; 77 \mathrm{uH} / 72 \mathrm{~V} ; 252 \mathrm{uH} / 120 \mathrm{v}$ \\
$(\mathbf{1 0 0 k H z})$ & \\
Speed & $2000-6000 \mathrm{rpm}$ \\
Weight & $17 \mathrm{~kg}$ \\
Casing & Aluminium \\
Dimmension $(\mathbf{h} * \boldsymbol{\phi})$ & $170 \mathrm{~mm} * 206 \mathrm{~mm}$ \\
\hline
\end{tabular}

Tabel 4.

Data spesifikasi fisik sepeda motor

\begin{tabular}{lll}
\hline \hline Parameter & Value & Unit \\
COG to rear & 735 & $\mathrm{~mm}$ \\
COG height & 764 & $\mathrm{~mm}$ \\
Wheelbase & 1.405 & $\mathrm{~mm}$ \\
Trail & 138 & $\mathrm{~mm}$ \\
Caster Angle & 25 & ${ }^{\circ}$ (degrees) \\
Head Tube Radius & 50 & $\mathrm{~mm}$ \\
Load Angle & 25 & ${ }^{\circ}$ (degrees) \\
Load Transfer Angle & 31,3 & ${ }^{\circ}$ (degrees) \\
Front Tire Radius & 294 & $\mathrm{~mm}$ \\
Rear Tire Radius & 313 & $\mathrm{~mm}$ \\
CoG & $(670,764)$ & \\
\hline \hline
\end{tabular}

Tabel 5.

Data spesifikasi kecepatan sepeda motor

\begin{tabular}{lll}
\hline \hline Parameter & Value & Unit \\
\hline Power & 20000 & Watt \\
& 26.80965 & $\mathrm{hp}$ \\
Radius (crown/gear belakang) & 0.121 & $\mathrm{~m}$ \\
Gear Ratio (motor : wheel) & 0.33 & \\
RPM motor & 6000 & $\mathrm{Rpm}$ \\
RPM wheel & 2000 & $\mathrm{Rpm}$ \\
& 209.3333 & $\mathrm{rad} / \mathrm{s}$ \\
Speed & 118.15 & $\mathrm{~km} / \mathrm{h}$ \\
Fcu & 1800 & $\mathrm{Newton}$
\end{tabular}

diperlukan platform rangka sepeda motor baru sebagai solusinya.

\section{RUMUSAN MASALAH}

Berdasarkan observasi langsung, studi literatur, dan wawancara terhadap demografi terkait, beberapa pokok pembahasan dalam riset ini adalah sebagai berikut:

1. Ekuivalensi tenaga motor listrik yang dibutuhkan untuk setara dengan mesin bakar $250 \mathrm{cc}$. 


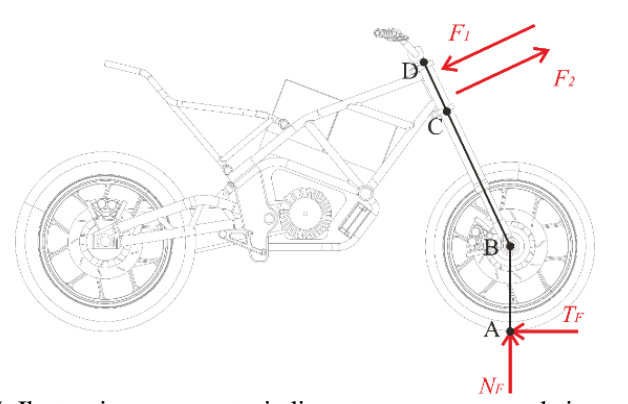

Gambar 5. Ilustrasi gaya yang terjadi saat pengereman maksimum.

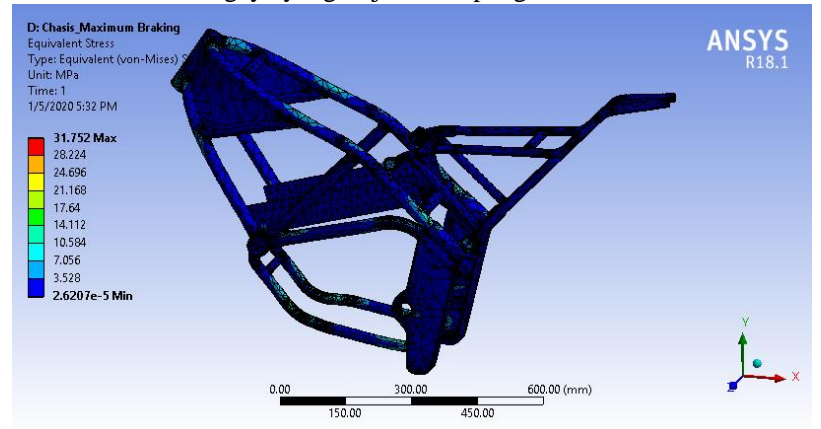

Gambar 6. Equivalent Stress, Max Braking.

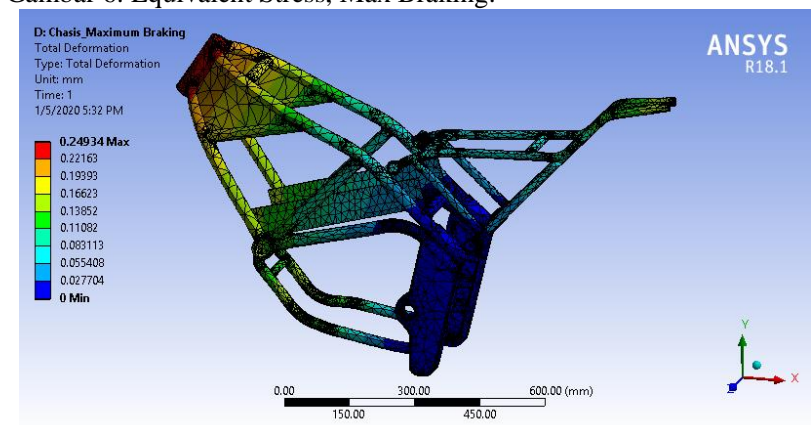

Gambar 7. Total Deformation, Max Braking.

2. Rangka yang dibuat dapat menahan tenaga yang setara dengan sepeda motor $250 \mathrm{cc}$.

3. Rangka dapat menjadi platform pengembangan desain berkelanjutan dalam hal ini mengakomodir modifikasi oleh masyarakat

\section{TINJAUAN PUSTAKA}

\section{A. Kebutuhan User}

Data diambil dari wawancara yang dilakukan kepada beberapa anggota komunitas penyuka sepeda motor yang memiliki sepeda motor dengan jenis sport. Dari data yang didapatkan dari wawancara tersebut, dapat diambil beberapa poin di bawah:

1. Sepeda motor yang dipakai hanya akan digunakan untuk berkendara santai di dalam kota.

2. Kecepatan rata-rata pada saat dalam kota umumnya sekitar $50 \mathrm{~km} / \mathrm{jam}$ dengan sesekali akan dipacu hingga $100 \mathrm{~km} / \mathrm{jam}$.

3. Modifikasi sepeda motor biasanya dilakukan ketika pemilik kendaraan sudah bosan dengan tampilannya.
Tabel 6.

Gaya eksternal saat akselerasi maksimum

\begin{tabular}{crl}
\hline \hline Maximum acceleration & Value & Unit \\
\hline $\mathrm{Nf}$ & 0 & Newton \\
$\mathrm{Nr}$ & 1860.85 & Newton \\
$\mathrm{Tr}$ & 1628.19 & Newton \\
\hline \hline
\end{tabular}

Tabel 7.

Gaya internal saat akselerasi maksimum

\begin{tabular}{crl}
\hline \hline Maximum acceleration & Value & Unit \\
\hline Vmaks & 25.33 & $\mathrm{~m} / \mathrm{s}$ \\
Fcb & 789.60 & Newton \\
F2 & 1433.84 & Newton \\
F1 & 712.46 & Newton \\
\hline \hline
\end{tabular}

Tabel 8

Gaya eksternal saat pengereman maksimum

\begin{tabular}{crl}
\hline \hline $\begin{array}{c}\text { Maximum Braking } \\
\text { at front axle }\end{array}$ & Value & Unit \\
\hline $\mathrm{Nf}$ & 1860.85 & Newton \\
$\mathrm{Nr}$ & 0 & Newton \\
$\mathrm{Tf}$ & 974.47 & Newton \\
\hline \hline
\end{tabular}

Tabel 9.

Gaya internal saat akselerasi maksimum

\begin{tabular}{crl}
\hline \hline $\begin{array}{c}\text { Maximum Braking } \\
\text { at front axle }\end{array}$ & Value & Unit \\
\hline AB & 294 & $\mathrm{~mm}$ \\
BC & 682.84 & $\mathrm{Mm}$ \\
$\mathrm{BD}$ & 835.21 & $\mathrm{~mm}$ \\
$\mathrm{CD}$ & 152.37 & $\mathrm{~mm}$ \\
$\mathrm{Nf}$ & 1860.85 & Newton \\
$\mathrm{Tf}$ & 974.47 & Newton \\
$\mathrm{F} 2$ & 2410.54 & Newton \\
$\mathrm{F} 1$ & 2313.80 & Newton \\
\hline \hline
\end{tabular}

\section{B. Penyetaraan Performa Mesin Bakar dan Motor Listrik}

Performa dari sepeda motor dapat diukur dari tenaga maksimum dan torsi maksimumnya. Tenaga pada mesin bakar diukur menggunakan satuan horsepower (hp). Sedangkan pada motor listrik menggunakan satuan watt (W). Dari kedua satuan tersebut, dapat disetarakan dengan $1 \mathrm{hp}=745,7 \mathrm{~W}$. Pada pengukuran torsi mesin bakar maupun motor listrik, satuan yang digunakan adalah newton-meter $(\mathrm{Nm})$.

Sample yang digunakan adalah seluruh sepeda motor dari kelas 250cc. Dengan batasan sepeda motor masih dijual di dealer per Januari 2020. Serta dilengkapi dengan nilai tenaga dalam satuan hp dan kilo Watt $(\mathrm{kW})$ dan torsi dengan satuan Nm yang dapat dilihat pada Tabel 1.

Dari data di atas, didapatkan rata-rata $28,8 \mathrm{hp}$ atau setara dengan 21,48 kW. Sehingga, jika disesuaikan dengan motor listrik yang ada di pasar, pilihan paling dekat adalah motor dengan tenaga maksimum $20 \mathrm{~kW}$ yang jika dikonversikan ke hp, didapatkan 26,8hp. 


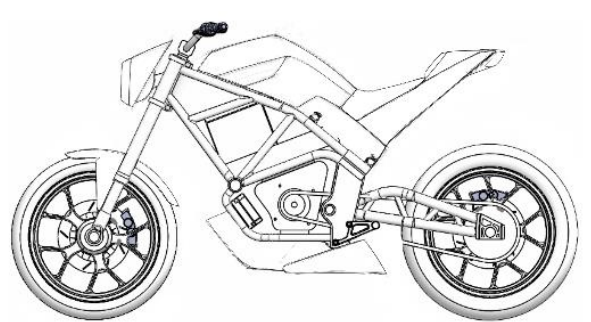

Gambar 8. Penggunaan rangka dengan gaya streetfighter.

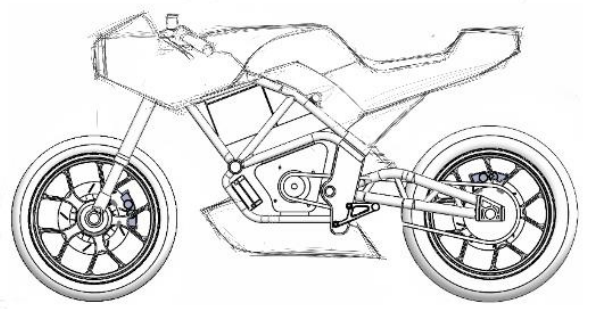

Gambar 9. Penggunaan rangka dengan gaya half fairing sportbike.

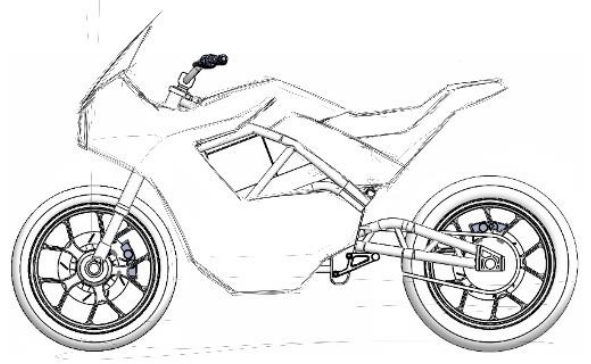

Gambar 10. Penggunaan rangka dengan gaya sport tourer.

\section{Jenis Rangka}

\section{1) Trellis}

Seringkali disebut tubular karena rangka ini menggunakan pipa yang disusun untuk membuat struktur rangka. Rangka jenis ini merupakan salah satu rangka yang paling kuat dan masih digunakan hingga saat ini. Proses pembuatan rangka jenis ini termasuk sulit karena selain pengelasan akan memakan waktu, diperlukan ketelitian. Namun pembuatan rangka jenis ini bisa dilakukan dengan murah karena tidak memerlukan banyak alat.

Rangka jenis ini umumnya menggunakan bahan steel. Sehingga masalah seperti korosi masih mungkin untuk terjadi. Selain itu material steel dapat menyebabkan massa sepeda motor tinggi sehingga akan mempengaruhi performa dan efisiensi mesinnya.

\section{2) Perimeter}

Merupakan salah satu rangka yang banyak dipakai oleh produsen sepeda motor karena proses pembuatannya lebih mudah dari trellis, sehingga akan mempermudah proses produksi massal. Secara teori, perimeter dan trellis memiliki prinsip yang sama namun dengan cara penyelesaian berbeda. Jika dieksekusi dengan baik, kedua frame juga dapat memiliki kekuatan yang sebanding.

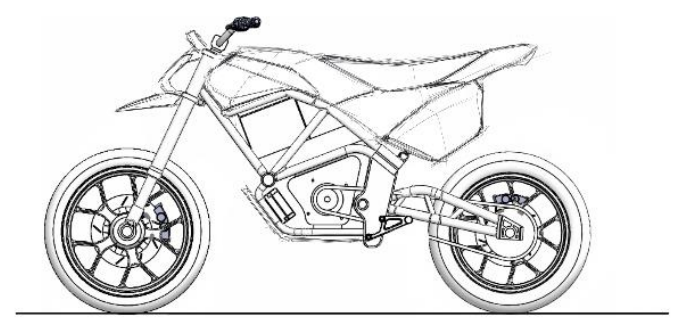

Gambar 11. Penggunaan rangka dengan gaya supermoto.

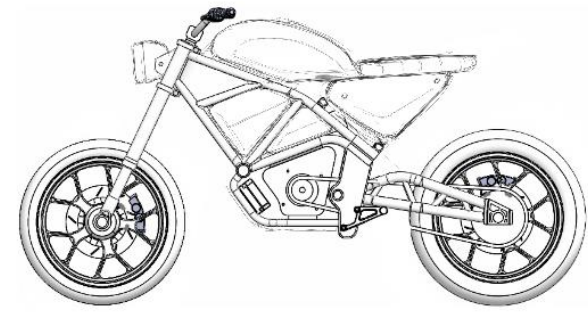

Gambar 12. Penggunaan rangka dengan gaya classic scrambler.

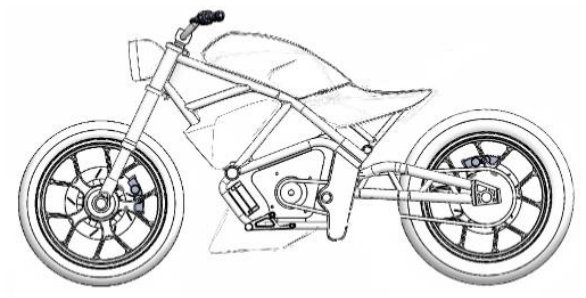

Gambar 13. Penggunaan rangka dengan gaya bobber.

Jenis Frame ini biasanya dibuatdari bahan aluminium dan dibuat dengan cara molding. Oleh karena itu pembuatan rangka jenis ini akan memerlukan alat dengan biaya yang besar.

\section{3) Monocoque}

Rangka ini memiliki massa yang sangat ringan namun kokoh. Hal ini tidak lain karena sifat bahan yang umumnya digunakan yakni carbon fiber. Rangka jenis ini dipakai pada sepeda motor sport dengan performa tinggi untuk mendapatkan benefit dari massanya. Namun rangka jenis ini memiliki harga yang tinggi. Hal ini karena bahan untuk membuat rangka jenis ini memiliki harga yang tinggi, dan proses pembuatannya yang sulit.

\section{Platform Rangka}

Platform rangka yang digunakan adalah rangka tubular yang didesain untuk menggunakan listrik sebagai sumber tenaganya. Rangka dilengkapi dengan mounting baterai pada bagian atas dan mounting motor pada bagian bawah (Gambar 2). Kelebihan rangka dengan jenis tubular adalah proses produksinya yang lebih murah jika diproduksi dalam jumlah terbatas dibandingkan dengan rangka jenis twin spar. Sehingga paling memungkinkan untuk dibuat. Selain itu rangka jenis ini terbukti kokoh dan dapat bersaing dengan rangka twin spar. Hal ini karena keduanya memiliki prinsip yang sama yakni 
menghubungkan head tube dengan poros swingarm dengan jarak terpendek dan mengitari mesin seperti pada Gambar 1.

Platform ini juga memiliki subframe yang dapat dilepas, sehingga modifikasi pada buritan sepeda motor ini akan lebih mudah dan lebih fleksibel.

Rangka yang dipakai akan menggunakan bahan stainless steel, dimana bahan tersebut dipakai supaya frame dapat bertahan lama dan terhindar dari korosi. Perhitungan massa chassis dilakukan pada software SolidWorks dengan massa di luar chassis diasumsikan sebesar $131 \mathrm{~kg}$ dapat dilihat pada Tabel 2.

\section{METODE}

Metode yang digunakan dalam riset ini adalah:

\section{1) Pengumpulan Data}

Pengumpulan data dilakukan pada dua kategori, pengumpulan data primer dan sekunder. Pengumpulan data primer dilakukan dengan cara wawancara kepada 3 jenis narasumber (komunitas, pemilik bengkel, dan produsen). Pada pengumpulan data sekunder, diambil dari literatur, jurnal dan website.

\section{2) Studi dan Analisis}

Studi dan analisis dilakukan untuk pembuktian dan penentuan teori yang akan digunakan dalam merancang rangka. Technical data untuk menentukan data teknis yang akan digunakan. Technical data diambil dari data yang telah tersaji untuk melihat keokohan rangka pada saat digunakan dan juga dilakukan studi terhadap gaya desain apa saja yang dapat diaplikasikan pada platform frame.

\section{STUDI DAN ANALISIS}

\section{A. Studi Spesifikasi Motor}

Berdasarkan hasil yang didapat dari wawancara, dapat disimpulkan jika performa maksimal kendaraan tidak akan digunakan secara terus menerus. Sehingga untuk meminimalisir penggunaan energi dan mengurangi biaya produksi, hanya diperlukan motor dengan tenaga kontinu dibawah 20kW.

Pada kasus ini, diasumsikan motor menggunakan produk dari Golden Motor dengan tenaga $10 \mathrm{~kW}$ kontinu, dengan range tenaga dari $8-20 \mathrm{~kW}$. Dengan motor tersebut, maka kriteria tenaga maksimum sebesar $20 \mathrm{~kW}$ telah terpenuhi. Spesifikasi dari Golden Motor $10 \mathrm{~kW}$ motor sendiri dapat dilihat pada Tabel 3.

Jika diasumsikan motor mencapai tenaga maksimalnya pada 6000rpm, maka dengan rumus di bawah dapat dicari torsi maksimum dari motor.

$T=P * 9.549 / n$

$T=20 * 9.549 / 6000$

$T=31.8 \mathrm{Nm}$

dimana

$T=$ torque $(\mathrm{Nm})$

$P=\operatorname{power}($ watts $)$

$n=$ revolution per minute $(\mathrm{rpm})$
Sehingga jika dibandingkan kembali dengan data sepeda motor kelas 250cc pada tabel 1, Motor listrik yang dipakai memiliki tenaga yang cukup untuk bersaing dengan kelas $250 \mathrm{cc}$ dan torsi yang lebih unggul dari sepeda motor di kelas $250 \mathrm{cc}$.

\section{B. Frame Structure Simulation}

Simulasi pada rangka yang telah dibuat, dilakukan pada software Ansys dengan analisis terhadap tekanan yang diterima rangka dan total deformasi pada saat akselerasi maksimum dan pengereman maksimum. Hal ini untuk mengetahui jika rangka memiliki titik lemah sehingga dapat diperbaiki untuk pengembangan lebih lanjut. Dari frame yang telah tersedia, dapat diambil data sebagai berikut yang dapat dilihat pada Tabel 4.

Untuk melengkapi data simulasi, diperlukan spesifikasi tenaga, torsi, dan kecepatan sepeda motor. Dengan asumsi rasio gear sebesar 1:3, didapatkan data sebagai berikut yang dapat dilihat pada Tabel 5.

Gaya yang terjadi pada saat akselerasi maksimum seperti pada Gambar 2.

Dari data di atas, hasil simulasi ditampilkan pada Gambar 3 - 4. Dengan hasil equivalent strees maksimum sebesar 65.649 MPa. Sedangkan total deformation sebesar $0.28621 \mathrm{~mm}$ yang dapat dilihat pada Tabel $6-7$.

Pada simulasi pengereman maksimum, data yang diperlukan untuk melakukan simulasi adalah sebagai berikut yang dapat dilihat pada Tabel 8 -9 dan diilustrasikan seperti pada Gambar 5.

Dari data di atas, hasil simulasi ditampilkan pada Gambar 6 - 7. Dengan hasil equivalent strees maksimum sebesar 31.752 MPa. Sedangkan total deformation sebesar $0.24934 \mathrm{~mm}$.

\section{Design Implementation}

Implementasi desain pada rangka dilakukan dengan mensimulasikan modifikasi yang mungkin dilakukan pada rangka sepeda motor yang telah dibuat. Batasan dari implementasi desain meliputi perubahan terhadap komponen body sepeda motor, mulai dari lampu, panel body, tangki, ekor, serta belly pan. Perubahan pada ketinggian kendaraan juga dapat dilakukan, namun tanpa merubah panjang dari main frame dan swing arm. Perubahan pada rangka dapat dilakukan hanya pada sub-frame karena part tersebut dapat mudah dilepas maupun diganti.

Simulasi modifkasi yang terapkan menggunakan referensi gaya desain sepeda motor streetfighter, half fairing sportbike, sport fairing, sport tourer, supermoto, classic scrambler, dan bobber seperti pada Gambar 8 - 13 .

\section{KESIMPULAN}

Sepeda motor dengan kelas 250cc memiliki tenaga dengan nilai yang berbeda satu dengan lainnya. Namun dari semua sepeda motor pada kelas tersebut dapat dilihat memiliki perbedaan yang tidak terlalu jauh. Sehingga dari data dapat disimpulkan batas minimal, maksimal dan rata-rata tenaga dari sepeda motor kelas tersebut. 
Dengan tenaga yang telah diketahui, disajikan motor dengan kemampuan yang sesuai dan simulasi pada rangka menunjukkan bahwa nilai tekanan dan deformasi yang terjadi pada rangka tidak signifikan karena sangat kecil. Namun dengan adanya deformasi tersebut, maka diperlukan penguatan terhadap beberapa bagian rangka yang menunjukkan warna merah pada hasil simulasi dan bagian yang masih biru dapat dioptimalkan untuk mengurangi massa rangka.

Dengan hasil simulasi yang telah memenuhi keamanan, dan implementasi desain yang dapat mencakup berbagai gaya desain sepeda motor, membuktikan bahwa rangka masih dapat dikembangkan lebih jauh dengan modifikasi minor maupun mayor baik dari produsen maupun masyarakat dengan cara modifikasi kustom yang dapat dilakukan di bengkel modifikasi umum. Namun modifikasi sepeda motor yang dilakukan nantinya akan tergantung pada pemilik dari sepeda motornya sendiri. Sehingga seiring dengan semakin banyaknya aliran desain yang muncul, diperlukan lebih evaluasi lebih lanjut untuk merealisasikan desain sepeda motornya.

\section{DAFTAR PUSTAKA}

[1] S. Kaleg, H. Abdul, and M. R. Kurnia, "Electric vehicle conversion based on distance, speed and cost requirements," in Energy Procedia, 2015, pp. $446-454$.

[2] S. Suprihati and W. B. Utami, "Analisis faktor - faktor yang mempengaruhi perilaku konsumen dalam keputusan pembelian mobil pribadi di kelurahan gonilan kabupaten sukoharjo," J. Paradig., vol. 13, no. 1, pp. 104-116, 2015.

[3] A. Ellaway, S. Macintyre, R. Hiscock, and A. Kearns, "In the driving seat: psychosocial benefits from private motor vehicle transport compared to public transport," Transp. Res. Part F Traffic Psychol. Behav., vol. 6, no. 3, pp. 217-231, 2003. 